\title{
Tetragenococcus solitarius
}

National Cancer Institute

\section{Source}

National Cancer Institute. Tetragenococcus solitarius. NCI Thesaurus. Code C86821.

A species of facultatively aerobic and microaerophilic, Gram positive, cocci shaped, lactic acid bacteria assigned to the phylum Firmicutes. This species is catalase and alkaline phosphatase negative and produces acid from $\mathrm{N}$ acetylglucosamine, amygdalin, cellobiose, fructose, mannose, mannitol and maltose. T. solitarius can be found in environments containing high levels of salt and has not been reported to be a human pathogen. 